further infant died later from pneumonia; there was no autopsy. Of the fourteen surviving children, twelve have been followed up for periods of $\mathrm{I}-4$ years. All twelve are free from symptoms and have apparently recovered completely. Two are still below the third percentile of weight for their age, three are in the roth percentile, three in the $25^{\text {th }}$, and four in the 5 oth. Only one is below the third percentile in height, three are in the third percentile, two in the Ioth, four in the 25 th, one in the

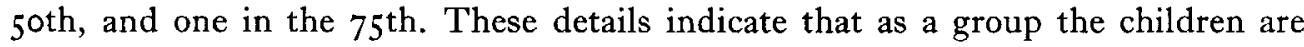
still below average height and weight, although they are not seriously retarded and it may be expected that they will achieve their expected growth levels in due course.

\title{
REFERENCES
}

Albright, F. \& Reifenstein, E. C. (1948). The Parathyroid Glands and Metabolic Bone Disease, p. 301. London: Baillière, Tindall and Cox.

Creery, R. D. G. (1953). Lancet, 265, i 7.

Creery, R. D. G. \& Neill, D. W. (1954). Lancet, 267, 1 10.

Hallman, N. (1955). Helv. paediat, acta, ro, I 19.

Jeans, P. C. \& Stearns, G. (1938). F. Pediat. 13, 730.

Lewis, J. M. (1935). F. Pediat. 6, 362.

Morgan, H. G., Mitchell, R. G., Stowers, J. M. \& Thomson, J. (1956). Lancet, 270, 925.

Rhaney, K. \& Mitchell, R. G. (r956). Lancet, 270, 1028.

Sinclair, H. M. (1956). Lancet, 271, IоI.

\section{Hypercalcaemia in infants and young animals}

\author{
By A. M. MacDonald, Royal Hospital for Sick Children, Glasgow
}

\section{Introduction}

The purpose of this paper is to discuss certain aspects of renal pathology in infants and in some young animals which may have a common aetiology. The material was derived from human-infant autopsies and animal experiments carried out on mice, rats, guinea-pigs, rabbits and calves with the strictly limited intention of comparing histological features in the kidneys in the different animal species under the conditions of the experiment with those found in the human infant.

Over the years there have been collected from routine autopsies in infants a series of observations on kidney lesions which in my experience are unlike any other lesion seen in the human infant.

The severe form has been adequately described and illustrated by Lowe, Henderson, Park \& McGreal (1954) and by Rhaney \& Mitchell (1956). Such a lesion invariably shows stainable calcium deposits, but with it a destructive granulomatous type of lesion is found often lacking in stainable calcium but nevertheless part of the disease process. Here one or more tubules are surrounded by granular debris in which round cells and few polymorph leucocytes and an occasional giant cell constitute the elements of the lesion. The surrounded tubule can be in any state of disintegration and sometimes is totally destroyed. Detailed examination of such 
an affected kidney will show several areas where the lesion is at its earliest and there seems to be little doubt that this early lesion will progress to calcinotic focal destruction. So not all lesions show stainable calcium deposits and the presence of calcium is not considered to be necessary in identifying the disease in its early stages.

This anomaly has been given the name of renal medullary calcinosis, a descriptive term and only applicable in its most severe form when a naked-eye diagnosis can be made. This lesion has been attributed to hypercalcaemia particularly.

During the past 2 years the numbers of florid cases seen by the pathologists have diminished materially owing to a better clinical recognition and treatment. In its early or mild form the histological lesion can still be found if looked for systematically in infants dying of a wide range of other diseases.

In hypophosphatasia, for example, blood examination shows a low phosphatase content and a high serum calcium level presumably dating from birth. In one case the serum calcium was $18 \mathrm{mg} / 100 \mathrm{ml}$, the child dying at $\mathrm{I}_{5}$ days of age showing no renal lesion beyond the presence of an occasional cast in the tubules; in another case, the child died at the age of 6 months with the full-blown lesion of renal medullary calcinosis. Even in this case there were indications of attempts at healing by scar tissue (Pl. I, I).

The kidney lesion was advanced in the second case because the child lived long enough for it to develop. It is suggested that at birth this kidney would have looked histologically normal as in the first case of hypophosphatasia (MacDonald \& Shanks, I957). Equally good examples of the gross lesions can be found in cases of gastroenteritis or of constipation. Such lesions are seen in known cases of hypercalcaemia (P1. I, 2).

The earliest histological pattern (P1. I, 3) has been recognized in forty-seven routine autopsies in infants in which the age range was from 4 to 18 months with a peak incidence at 9 months.

These forty-seven cases were from a series of 326 consecutive deaths in children of the same age group and represent an incidence of $14.4 \%$ with a ratio of males to females of $4: 3$. Unfortunately since serum-calcium estimations were not carried out in these cases with early lesions no direct correlation can be made. To provide an indirect correlation animal experiments were devised.

\section{Animal experiments}

In order to produce renal calcinosis experimentally in animals large doses of vitamin $\mathrm{D}_{3}$ were given. Lesions have been produced in the kidneys of five different species of animal-calf, rabbit, guinea-pig, rat and mouse. The exceptional dosage calculated to produce hypercalcaemia with certainty is, of course, greatly in excess of those normally given to infants. Vitamin $D_{3}$ was added to a normal diet so that there was no complicating effect of any deficiency, for example of magnesium. The animals were killed at intervals in order to ascertain the evolution of the kidney lesion with emphasis on the comparison between the early experimental lesions and those seen in infants. No claim is made that the renal lesion is the only one. Much 
of the recent experimental work on hypervitaminosis $D$ is concerned with metastatic calcification with little regard for the part played by the kidney (Eisenstein \& Groff, 1957).

In the mouse, given 100 i.u. vitamin $D_{3}$ from the day after birth for 14 days an early medullary lesion can be produced. Dilatation of tubules was a prominent feature and there were a few casts.

If administration of vitamin $\mathrm{D}$ was begun when the mouse was 28 days old and continued daily for 22 days, medullary calcinosis was severe. In this connexion it should be remembered that most human infants begin on mother's milk and only later does the intake of vitamin $\mathrm{D}$ rise.

In the rat, given 100 i.u. vitamin $\mathrm{D}_{3}$ for ${ }_{5} 5$ days from 6 days of age, the amorphous granulomatous mass similar to the lesion in the human infant can be produced. The site of the lesion is in the medulla. At this age cortical lesions are also present. The medullary lesion is more clearly defined after 33 days' feeding, when stainable calcium is seen in the tubular cells and in the lumen.

In the guinea-pig, given 2000 i.u. vitamin $D_{3}$ from birth for 14 days there are early cortical tubular calcium deposits and tubular dilatation with a few medullary lesions confined to tubular dilatation and minor interstitial damage.

In the rabbit, given 6000 i.u. vitamin $\mathrm{D}_{3}$ from birth for I I days, cortical lesions localized to the peripheral tubules were predominant in some, whereas in others the lesion was dominantly medullary at the same age. In a rabbit given 2000 i.u. from birth for 25 days and with the serum calcium level of $18.8 \mathrm{mg} / \mathrm{I} 00 \mathrm{ml}$., an early lesion was obtained in the medulla exactly like that seen in the infant (P1. I, 4).

Lastly, in the calf, given doses of $1,000,000$ i.u. daily for 60 days both active and fibrosing medullary lesions were produced (P1. I, 5,6) which were similar to those seen in the infant. In another calf receiving the same dosage the calcinosis was so severe that glomeruli were affected. This demonstrates the variety of response in the dosage given, a finding common to all the animals used in the experiment.

\section{Discussion}

To sum up the evidence from the animal work it would appear that a histological picture known to be related to the intake of vitamin $\mathrm{D}_{3}$ can be produced with features very similar in all animals used. Attention has been directed particularly to the early lesion which in all animals was similar to that found in routine examination of human infants.

The renal lesion is more easily produced in an animal which has passed the neonatal period but has not yet been weaned. It is significant that the age range in the human-infant series was 4 months to 18 months.

It would be wrong to suggest that vitamin $\mathrm{D}$ is the only factor operating to produce this lesion since milk, as a major constituent of otherwise normal diets, is conducive to production of hypercalcaemia. Certainly cases of hypercalcaemia in infants fed only on human milk are known from personal experience. Milk was not given to the laboratory animals. Nevertheless, it seems likely that vitamin D is an aetiological factor. 

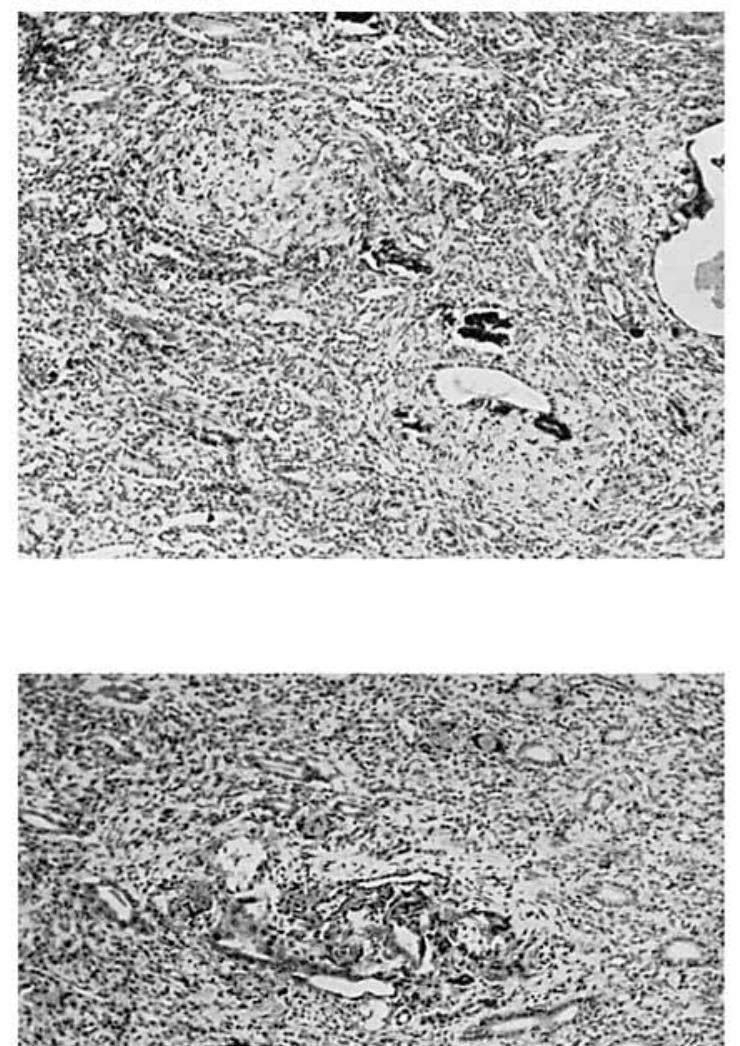

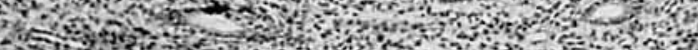

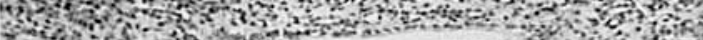

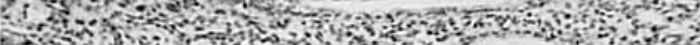

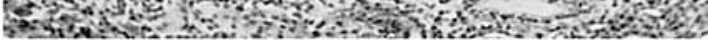

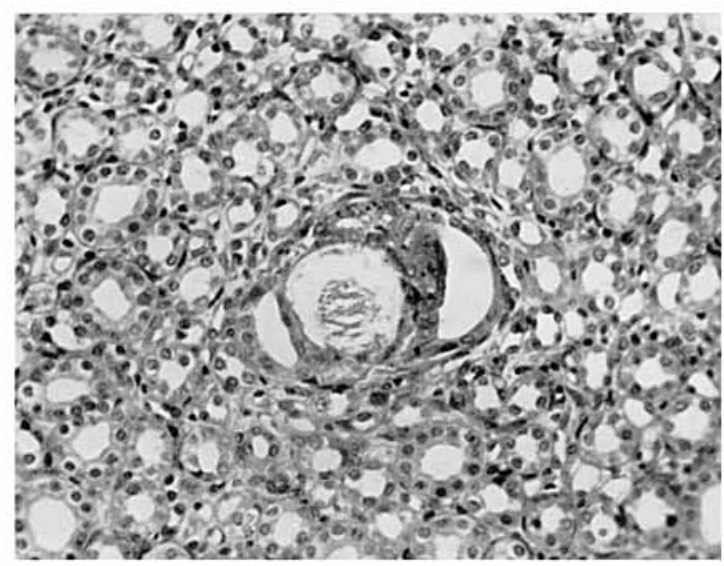

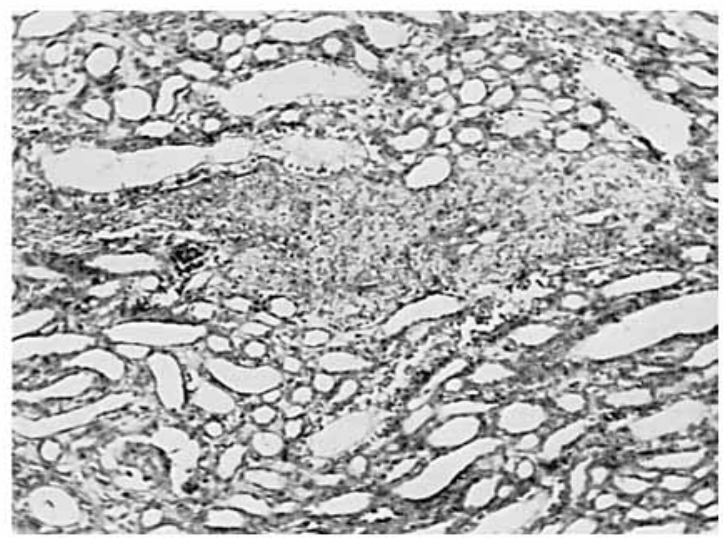

Proceedings of The Nutrition Society, Vol. I 7, No. I 
From common paediatric experience it is known that foodstuffs supplemented with vitamin $\mathrm{D}$ are used in virtually every infant's diet. Very often doses of $3000-$ 4000 i.u. vitamin $\mathrm{D}$ are taken daily and often much higher ones. The accepted dose to prevent rickets is 700 i.u. (British Paediatric Association, 1943). Goodman \& Gillman (1955) consider $15^{\circ}, 000$ units daily toxic for a child, and in the rare examples in the literature where deaths due to vitamin $\mathrm{D}$ overdosage are cited renal disturbance (Grundler, 1955) and renal calcinosis (Debré, 1948) have been described. In the latter case II million i.u. were given. Though it is known that the majority of infants show no clinical effects during the time they are subjected to minor excesses of vitamin $\mathrm{D}$, the numbers of infants dying from widely different causes, having this renal lesion, suggests that either the lesion is self-limiting or that where the lesion is found the kidney is inefficient in coping with the excess of calcium or, to put it another way, hypercalcaemia in children is common perhaps owing to vitamin $\mathrm{D}$ additives in food. This is of some clinical importance, although hypercalcaemia seldom causes death, and in any event can be corrected by a low calcium intake in the diet or by cortisone therapy.

I wish to thank Dr K. L. Blaxter for the calf tissue supplied to me.

\section{REFERENCES}

British Paediatric Association. (1943). Arch. Dis. Childh. 18, 58.

Debré, R. (1948). Amer. F. Dis. Child. 75, 787.

Eisenstein, R. \& Groff, W. A. (1957). Proc. Soc. exp. Biol., N.Y., 94, 441.

Goodman, L. S. \& Gillman, A. (1955). The Pharmacological Basis of Therapeutics, and ed., p. 1738. New York: The Macmillan Company.

Grundler, E. (1955). Dtsch. med. Wschr. 80, 285.

Lowe, K. G., Henderson, J. L., Park, W. W. \& McGreal, D. A. (1954). Lancet, 267, 101.

MacDonald, A. M. \& Shanks, R. A. (1957). Arch. Dis. Child. 32, 304.

Rhaney, K. \& Mitchell, R. G. (1956). Lancet, 270, 1028.

\section{EXPLANATION OF PLATE}

I. Kidney of child. Stained haematoxylin and eosin. Evidence of healing. $x \mathbf{7 5}$.

2. Kidney of child. Stained haematoxylin and eosin. Focal lesion in known case of hypercalcaemia. $\mathrm{x} 72$.

3. Kidney of child. Stained haematoxylin and eosin. Early medullary lesion. $\mathbf{x} 323$.

4. Kidney of rabbit. Stained haematoxylin and eosin. An early medullary lesion. $x 200$.

5. Kidney of calf. Stained haematoxylin and eosin. Early granulomatous lesion in the medulla. $\mathbf{x} 200$.

6. Kidney of calf. Stained haematoxylin and eosin. Fibrosing medullary lesion. $\mathbf{x} \mathbf{7 2}$. 